\title{
PEMANFAATAN SOFTWARE GRAPH 4.4.2 DALAM MENUNJANG PERKULIAHAN GEOMETRI ANALITIK
}

\author{
Tabah Heri Setiawan
}

\author{
Program Studi Matematika, FMIPA - UNPAM \\ dosen00527@unpam.ac.id/tabah.ibnubara@gmail.com
}

\begin{abstract}
The use of technology, especially in the field of ICT, can be developed to develop learning models and innovations. In mathematics lectures, students and lecturers can use Graph Graph 4.4.2 for analytical geometry lectures. To find out how effective the use of software graph 4.4 .2 can be examined using testing the average difference (u-test) between classes using software Graph 4.4.2 with classes that do not use software Graph 4.4.2 (classical). From the results of the study obtained the sig value. in the t-test of 0,000, the t-value is 4,402 and the average gain score is 0,74. From these results it can be concluded that there are significant differences between learning outcomes before using software graph 4.4.2 with learning outcomes after using software graph 4.4.2 in analytical geometry lectures, where the average value of the experimental class using software graph 4.4.2 is in the process learning is far better compared to the control class in the learning process without using software graph 4.4.2.
\end{abstract}

Keywords: Analytical Geometry, Software Graph 4.4.2, T-test.

\begin{abstract}
ABSTRAK
Pemanfaatan teknologi khususnya dalam bidang ICT dapat dikembangkan untuk menyusun model serta inovasi pembelajaran. Dalam perkuliahan matematika, mahasiswa dan dosen dapat menggunakan software Graph 4.4.2 untuk perkuliahan geometri analitik. Untuk mengetahui seberapa efektif pemanfaatan software graph 4.4.2 dapat diteliti menggunakan pengujian selisih rata-rata (uji-u) antara kelas yang menggunakan software Graph 4.4.2 dengan kelas yang tidak menggunakan software Graph 4.4.2 (klasikal). Dari Hasil penelitian diperoleh nilai sig. pada uji-t sebesar 0,000 , nilai thitung sebesar 4,402 dan skor gain rata-rata sebesar 0,74 . Dari hasil tersebut dapat disimpulkan terdapat perbedaan yang signifikan antara hasil belajar sebelum menggunakan software graph 4.4.2 dengan hasil belajar setelah menggunakan software graph 4.4.2 dalam perkuliahan geometri analitik, dimana rata-rata nilai kelas eksperimen yang menggunakan software graph 4.4.2 dalam proses pembelajaran jauh lebih baik dibandingan dengan kelas kontrol yang dalam proses belajar tanpa menggunakan software graph 4.4.2..
\end{abstract}

Kata kunci: Geometri Analitik, Software Graph 4.4.2, Uji-T. 


\section{PENDAHULUAN}

\subsection{Latar Belakang Masalah}

Geometri merupakan salah satu cabang dari ilmu matematika yang diajarkan di tingkat sekolah baik dari sekolah dasar maupun sekolah menengah, sedangkan di tingkat perguruan tinggi geometri diajarkan pada mahasiswa di fakultas teknik dan mipa. Terlebih pada program studi (prodi) matematika baik matematika murni, terapan maupun pendidikan, geometri mendapat porsi pengajaran yang lebih dibanding prodi-prodi lainnya. Hal ini dikarenakan geometri merupakan salah satu sub disiplin ilmu matematika yang paling banyak terbangun dari teorema-teorema matematika. Dalam memudahkannya pengajarannya khususnya di perguruan tinggi, geometri dibagi dalam geometri datar/bidang, geometri ruang serta geometri analitik. Sedangkan dalam pendidikan dasar dan menengah digunakan istilah bangun datar atau dua dimensi untuk geometri datar dan bangun ruang atau tiga dimensi untuk geometri ruang.

Dalam semua cabang keilmuan matematika, kemampuan dasar yang harus dikuasai untuk memahami matematika adalah pemahaman konsep dan pemecahan masalah. Akan tetapi untuk geometri selain harus menguasai pemahan konsep dan pemecahan masalah adalah memiliki kemampuan berpikir visual dan spasial (Visual-Spatial Thinking). Bila dalam berpikir visual-spasial untuk geometri masih rendah maka dapat dipastikan konsep dan pemecahan masalah yang akan digunakan pasti keliru. Hal inilah yang ditengarai sebagai penyebab dari rendahnya nilai geometri dikalangan siswa dan mahasiswa. Oleh karena itu banyak sekali tenaga pendidik baik guru maupun dosen yang selalu bereksperimen menemukan cara untuk bisa meningkatkan kemampuan berpikir visualspasial peserta didik agar bisa meningkatkan hasil belajar (nilai) untuk materi/mata kuliah geometri. Salah satu langkah yang sering diambil adalah dengan memanfaatkan media pembelajaran yang interaktif.

Seiring perkembangan zaman dimana kita memasuki era teknologi informasi dan era digital yang mana hampir semua lini kehidupan sudah tersentuh dengan adanya teknologi informasi dan komunikasi. Salah satu bidang kehidupan yang terkena dampak teknologi informasi adalah bidang pendidikan yang penerapannya banyak pada penggunaan media pembelajaran berbasis ICT (Information and Communication Tecnology). Pembelajaran yang dahulu dilakukan secara konvensianal diganti dengan teknologi komputer. Salah satunya adalah pada bidang geometri dimana untuk memvisualkan gambaran bentuk geometri baik dua dimensi maupun tiga dimensi cukup dengan menggunakan perangkat lunak atau software yang nantinya ditampilkan melalui layar.

Meskipun demikian masih minim sekali inovasi yang dilakukan oleh guru/dosen/tutor dalam mengembangkan pembelajaran berbasis ICT terutama dalam pembelajaran matematika baik di jenjang sekolah dasar, menengah, mapun di tingkat 
perguruan tinggi. Selain itu banyak software matematika yang diberedar di pasaran harganya tergolong mahal bagi kalangan akademisi. Lihat saja software Matlab yang sangat mendunia dalam bidang matematika dan teknik untuk edisi mahasiswa pada sebuah situs jual beli online dijual Rp 3.800.000/user. Sedangkan untuk Maplesoft dibandrol Rp 1.650.000 atau \$124 dan untuk mathematica Rp 1.995.000 atau \$150/tahun. Harga-harga tersebut hanya untuk mahasiswa, terbilang murah jika harus membeli edisi profesional, meskipun murah tetap saja terhitung mahal bagi kebanyakan mahasiswa indonesia.

Untuk mengatasi hal tersbut di atas banyak sekali relawan-relawan baik perorangan maupun kelompok yang bergerak dalam bidang IT dan matematika membuat softwaresoftware yang gratis alias tak berbayar. Sebut saja seperti Geogebra yang sangat tidak asing dikalangan mahasiswa matematika. Software ini memadukan antara aljabar dengan geometri dan visualisasi geometri yang elegan baik dua dimensi maupun tiga dimensi..

Selain geogebra ada satu lagi software besutan Informer Technologies, Inc yang spesifik memvisualisasikan geometri khususnya bangun dimensi dua yakni Software Graph. Software yang rilis terakhir dengan nama Graph 4.4.2 ini fokus pada tampilan yang sederhana dan mudah dioperasikan sehingga bagi pengguna sangat user friendly bahkan oleh yang masih awam sekalipun. Bahkan software ini sifatnya open source yang artinya dapat dikembangkan oleh siapapun termasuk kita asalkan memiliki basic bahasa pemrograman yang cukup matang. Meskipun software ini tak sepopuler geogebra, akan tetapi tidak salahnya aplikasi ini digunakan dan dimanfaatkan untuk membantu proses pembelajaran geometri khususnya geometri datar.

Oleh karena itu, penulis memandang perlu melakukan riset berupa treatment atau perlakuan serta pengamatan terhadap mahasiswa Program Studi Matematika FMIPA UNPAM khususnya semester 5 pada mata kuliah Geometri Analitik untuk melihat seberapa efektifkah pemanfaatan software graph 4.4.2 pada perkuliahan Geometri khususnya Geometri Analitik dalam meningkatkan hasil belajar mahasiswa.

Berdasarkan uraian di atas, maka peneliti mencoba untuk melakukan penelitian yang berjudul "Pemanfaatan Software Graph 4.4.2 Dalam Menunjang Perkuliahan Geometri Analitik".

\subsection{Rumusan Masalah}

Berdasarkan identifikasi dan batasan masalah yang telah diuraikan di atas, selanjutnya perumusan masalah dalam penelitian ini adalah:

1) Apakah terdapat perbedaan yang signifikan antara hasil belajar sebelum menggunakan software graph 4.4.2 dengan hasil belajar sesudah menggunakan software graph 4.4.2 dalam perkuliahan geometri analitik? 
2) Seberapa efektifkah pemanfaatan software graph 4.4.2 dalam menunjang perkuliahan geometri analitik?

\subsection{Tujuan Penelitian}

Dari rumusan masalah di atas maka penelitian ini bertujuan untuk :

1) Mengetahui ada tidaknya perbedaan yang signifikan antara hasil belajar sebelum menggunakan software graph 4.4.2 dengan hasil belajar sesudah menggunakan software graph dalam perkuliahan geometri analitik.

2) Mengetahui tingkat efektifitas pemanfaatan software graph 4.4.2 dalam menunjang perkuliahan geometri analitik.

\subsection{Manfaat Penelitian}

Manfaat praktis dari penelitian ini adalah untuk mengetahui keefektifan penggunaan media pembelajaran berbasis ICT dengan bantuan software graph 4.4.2 sebagai alat bantu pembelajaran agar memudahkan mahasiswa memahami geometri analitik dalam upaya meningkatkan hasil belajar mahasiswa di bidang geometri. Manfaat teoritis dari penelitian ini adalah untuk digunakan bagi kemajuan dan pengembangan ilmu pengetahuan sebagai bahan referensi, serta untuk pengembangan penelitian tentang hal sama pada masa selanjutnya..

\section{METODOLOGI PENELITIAN}

\subsection{Waktu dan Tempat Penelitian}

Tempat yang digunakan untuk melakukan penelitian ini adalah Universitas Pamulang pada Program Studi Matematika S1 Fakultas Matematika dan Ilmu Pengetahuan Alam (FMIPA). Adapun waktu pelaksanaan penelitian ini dilakukan dalam rentang satu bulan dari 12 September 2017 sampai dengan 17 Oktober 2017.

\subsection{Populasi dan Sampel}

Dalam penelitian ini populasinya adalah seluruh mahasiswa yang berada pada semester 5, karena mata kuliah geometri analitik di ajarkan pada semester ke-5. Sehingga jumlah populasinya secara keseluruhan berjumlah 106 mahasiswa yang terbagi dalam 5 kelas (1 kelas reguler A, 2 kelas reguler B dan 2 kelas reguler C).

Untuk menentukan sampel, dikarenakan metode penelitian menggunakan quasi experimen maka penetapan jumlah sampel didasarkan pada jumlah mahasiswa sesuai dengan kelas yang ada. Untuk memudahkan maka dipilihkan 2 kelas yaitu kelas 05MATP001 dengan 17 mahasiswa dan kelas 05MATM001 dengan 15 mahasiswa. Jadi total sampel yang digunakan sebesar 32 mahasiswa. 


\subsection{Jenis dan Teknik Pengumpulan Data}

Pada penelitian ini data yang dipakai adalah data primer. Data primer adalah data yang diperoleh langsung dari sumbernya, diamati dan dicatat untuk pertama kalinya. Data primer pada penelitian ini diperoleh dengan memberikan tes tertulis kepada mahasiswa. Skor yang diberikan akan memberikan gambaran langsung tentang pemahamn mahasiswa tentang geometri analitik.

\subsection{Variabel Penelitian}

Variabel adalah konsep yang mempunyai variabilitas. Konsep merupakan penggambaran/abstrak dari fenomena tertentu sehingga pada akhirnya variabel merupakan segala sesuatu yang bervariasi (Yaya Suryana, 2015). Variabel dalam penelitian ini ada 4 yakni:

$\mathrm{O}_{1} \quad$ : Nilai pre-test pada Kelas Kontrol

$\mathrm{O}_{2} \quad$ : Nilai pre-test pada Kelas Experimen

$\mathrm{O}_{3} \quad$ : Nilai post-test pada Kelas Kontrol

$\mathrm{O}_{4} \quad$ : Nilai post-test pada Kelas Experimen

Kelas kontrol adalah keseluruhan mahasiswa yang ada di kelas 05MATM001 sejumlah 15 mahasiswa sedangkan kelas eksperimen adalah keseluruhan mahasiswa pada kelas 05MATP001 yang berjumlah 17 mahasiswa.

\subsection{Desain Penelitian}

Desain atau rancangan penelitian yang digunakan pada penelitian ini adalah dengan menggunakan Nonequivalent Control Group Design. Penelitian ini melibatkan dua kelas yaitu kelas eksperimen dan kelas kontrol, dimana kedua kelas ini diberikan perlakuan yang berbeda. Untuk mengetahui hasil belajar geometri analitik mahasiswa diperoleh dari tes yang dilakukan sebanyak dua kali yaitu sebelum (pre-test) dan sesudah perlakuan (post-test).

Desain penelitian seperti ditunjukkan pada Tabel berikut ini.

Tabel 2.1. Nonequivalent Control Group Design

\begin{tabular}{|ccc|}
\hline $\mathrm{O}_{1}$ & -- & $\mathrm{O}_{3}$ \\
$\mathrm{O}_{2}$ & $\mathrm{X}$ & $\mathrm{O}_{4}$ \\
\hline
\end{tabular}

Keterangan:

$\mathrm{O}_{1} \quad$ : Nilai pre-test pada Kelas Kontrol

$\mathrm{O}_{2} \quad$ : Nilai pre-test pada Kelas Experimen

$\mathrm{O}_{3} \quad$ : Nilai post-test pada Kelas Kontrol 
$\mathrm{O}_{4} \quad$ : Nilai post-test pada Kelas Experimen

--- $\quad$ : Tanpa perlakuan (treatment)

X $\quad$ : Perlakuan (treatment)

\subsection{Teknik Analisis Data}

Dalam penelitian ini data yang diolah adalah data kuantitatif yang dianalisis secara statistik. Secara umum, pengolahan dan analisis data kuantitatif dari hasil belajar geometri analitik, dilakukan dengan langkah-langkah berikut:

\subsubsection{Analisis Deskriptif}

Langkah-langkah yang dilakukan pada tahap deskripsi data ini adalah membuat tabulasi data untuk setiap kelasbaik kelas kontrol maupun kelas eksperimen, mengurutkan data secara interval dan menyusunnya dalam bentuk tabel distribusi frekuensi dan grafik histogram dan poligon, mencari rata-rata (mean), modus, median, simpangan baku, dan varians data. Deskripsi data dilakukan dengan menggunakan program komputer IBM SPSS Statistic 25.

\subsubsection{Uji Prasyarat Analisis}

\section{a.Uji Normalitas}

Uji normalitas data dilakukan untuk mengetahui apakah data dari masing-masing kelompok berdistribusi normal atau tidak. Normalitas data diperlukan untuk menentukan uji statistik data dari kelompok sampel yang digunakan. Untuk menguji normalitas data, digunakan uji Shapiro Wilk yang dilakukan dengan berbantuan software IBM SPSS Statistics 25. Adapun hipotesis dan kriteria ujinya adalah:

$\mathrm{H}_{0} \quad$ : Sampel berdistribusi normal

$\mathrm{H}_{\mathrm{a}} \quad$ : Sampel tidak berdistribusi normal

Kriteria pengujian tolak $\mathrm{H}_{0}$ jika nilai signifikansi uji statistik Shapiro Wilk <0,05.

\section{b.Uji Homogenitas Varians}

Uji homogenitas varians dilakukan untuk mengetahui apakah tiap-tiap kelompok data maupun data keseluruhan memiliki variansi yang homogen atau tidak. Untuk menguji homogenitas varians data, digunakan uji statistik Levene's yang dilakukan dengan berbantuan software IBM SPSS Statistics 25. Adapun hipotesis dan kriteria ujinya adalah:

$\mathrm{H}_{0} \quad$ : Varians antar kelompok data homogen

$\mathrm{H}_{\mathrm{a}} \quad$ : Varians antar kelompok data tidak homogen

Kriteria pengujian : tolak $\mathrm{H}_{0}$ jika nilai signifikansi uji statistik Levene's $<0,05$. 


\subsubsection{Uji Hipotesis Penelitian}

Untuk mengetahui ada tidaknya perbedaan yang signifikan antara kelas eksperimen dengan kelas kontrol maka dapat menggunakan uji-t untuk sampel tidak berpasangan. Adapun rumus yang digunakan adalah rumus 2.2.

$$
t=\frac{\bar{X}_{A}-\bar{X}_{B}}{\sqrt{\frac{S_{A}^{2}}{n_{A}}+\frac{S_{B}^{2}}{n_{B}}}}
$$

Sedangkan jika data yang digunakan tidak berdistribusi normal maka dapat menggunakan uji U Mann-Whitney.

Hipotesis yang diajukan adalah sebagai berikut:

$\mathrm{H}_{0} \quad$ : Rata-rata hasil belajar geometri analitik kelas eksperimen tidak lebih baik dibandingkan kelas kontrol.

$\mathrm{H}_{\mathrm{a}}$ : Rata-rata hasil belajar geometri analitik kelas eksperimen lebih baik dibandingkan kelas kontrol.

Untuk memudahkan perhitungan digunakan software IBM SPSS 25, dimana $\mathrm{H}_{0}$ ditolak jika nilai sig. $<0,05$.

Sedangkan untuk mengetahui seberapa efektif penggunaan software graph dalam meningkatkan pemahaman materi geometri analitik melalui ujian tertulis menggunakan Uji Normalitas Gain dengan rumus 2.12.

$$
g=\frac{S_{\text {post-test }}-S_{\text {pre-test }}}{S_{\max }-S_{\text {pre-test }}}
$$

Tinggi rendahnya gain yang dinormalisasi ( $\mathrm{N}$-gain) dapat diklasifikasikan sebagai berikut:

(1) jika $g \geq 0,7$, maka $\mathrm{N}$-gain yang dihasilkan termasuk kategori tinggi;

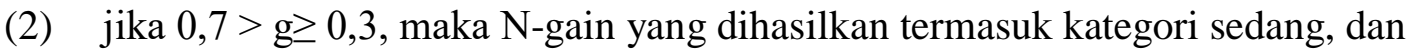

(3) jika g < 0,3 maka $\mathrm{N}$-gain yang dihasilkan termasuk kategori rendah.

\section{HASIL DAN PEMBAHASAN}

\subsection{Deskripsi Data}

Data diambil sebanyak dua kali pada masing-masing kelas baik kelas kontrol maupun kelas eksperimen, yang pertama pre-test dan yang kedua post-test. 
Tabel 3.1 Hasil Pre-Test

\begin{tabular}{|c|c|c|}
\hline Nomor & $\begin{array}{c}\text { Kelas Kontrol } \\
\mathbf{O}_{\mathbf{1}}\end{array}$ & $\begin{array}{c}\text { Kelas Eksperimen } \\
\mathbf{O}_{\mathbf{2}}\end{array}$ \\
\hline 1 & 27,5 & 25 \\
\hline 2 & 35 & 45 \\
\hline 3 & 15 & 30 \\
\hline 4 & 35 & 25 \\
\hline 5 & 25 & 25 \\
\hline 6 & 32,5 & 30 \\
\hline 7 & 42,5 & 17,5 \\
\hline 8 & 40 & 15 \\
\hline 9 & 20 & 30 \\
\hline 10 & 35 & 25 \\
\hline 11 & 30 & 40 \\
\hline 12 & 45 & 25 \\
\hline 13 & 37,5 & 32,5 \\
\hline 14 & 30 & 30 \\
\hline 15 & 35 & 45 \\
\hline 16 & & 37,5 \\
\hline 17 & & 50 \\
\hline & & \\
\hline
\end{tabular}

Dengan menggunakan SPSS diperoleh deskripsi data untuk pre-test sebagai berikut:

Tabel 3.2 Deskripsi Data Pre-Test

\begin{tabular}{lrrr} 
& \multicolumn{2}{c}{ Statistics } \\
& Kelas Kontrol & \multicolumn{2}{c}{$\begin{array}{c}\text { Kelas } \\
\text { Eksperimen }\end{array}$} \\
\hline $\mathrm{N}$ & 15 & 17 \\
\cline { 2 - 4 } & Valid & 2 & 0 \\
\hline Mean & 32,3333 & 31,0294 \\
\hline Std. Error of Mean & 2,09118 & 2,34892 \\
\hline Median & 35,0000 & 30,0000 \\
\hline Mode & 35,00 & 25,00 \\
\hline Std. Deviation & 8,09909 & 9,68483 \\
\hline Variance & 65,595 & 93,796 \\
\hline Skewness &,- 600 &, 435 \\
\hline Std. Error of Skewness &, 580 &, 550 \\
\hline Kurtosis &, 258 &,- 344 \\
\hline Std. Error of Kurtosis & 1,121 & 1,063 \\
\hline Minimum & 15,00 & 15,00 \\
\hline Maximum & 45,00 & 50,00 \\
\hline Sum & 485,00 & 527,50 \\
\hline
\end{tabular}


Dari tabel 3.2 dapat diperoleh gambaran data bahwa data yang diambil sebagai pretest memiliki rata-rata yang selisihnya tidak terlalu jauh dimana rata-rata nilai pre-test untuk kelas kontrol sebesar 32,3333 sedangkan rata-rata nilai pre-test untuk kelas eksperimen sebesar 31,0294. Meskipun demikian pembuktian secara inferensial akan dibahas pada sub bab berikutnya. Begitu juga dengan nilai standar deviasi dimana kelas kontol dan kelas eksperimen memiliki standar deviasi sebesar 8,09909 dan 9,68483. Nilai tersebut cukup besar (diatas $20 \%$ dari nilai mean) menunjukan variasi yang besar. Sementara itu untuk nilai skewness dan kurtosis kedua kelas menunjukan nilai yang mendekati nol (0), sehingga dapat diasumsikan bahwa distribusi data baik kelas kontrol maupun kelas eksperimen berdistribusi normal. Akan tetapi pembuktian secara inferensial akan dijabarkan pada sub-bab berikutnya.

Untuk data post-test disajikan dalam tabel berikut:

Tabel 3.3 Hasil Post-Test

\begin{tabular}{|c|c|c|}
\hline Nomor & $\begin{array}{c}\text { Kelas Kontrol } \\
\mathbf{O}_{\mathbf{1}}\end{array}$ & $\begin{array}{c}\text { Kelas Eksperimen } \\
\mathbf{O}_{\mathbf{2}}\end{array}$ \\
\hline 1 & 50 & 70 \\
\hline 2 & 70 & 90 \\
\hline 3 & 45 & 75 \\
\hline 4 & 75 & 75 \\
\hline 5 & 50 & 65 \\
\hline 6 & 65 & 75 \\
\hline 7 & 80 & 70 \\
\hline 8 & 70 & 70 \\
\hline 9 & 50 & 80 \\
\hline 10 & 70 & 70 \\
\hline 11 & 70 & 97 \\
\hline 12 & 65 & 75 \\
\hline 13 & 70 & 85 \\
\hline 14 & 60 & 75 \\
\hline 15 & 50 & 90 \\
\hline 16 & & 80 \\
\hline 17 & & 95 \\
\hline
\end{tabular}

Dengan menggunakan SPSS diperoleh deskripsi data untuk post-test sebagai berikut: 
Tabel 3.4 Deskripsi Data Post-Test

\begin{tabular}{lrrr} 
& \multicolumn{2}{c}{ Statistics } \\
& Kelas Kontrol & $\begin{array}{c}\text { Kelas } \\
\text { Eksperimen }\end{array}$ \\
\hline $\mathrm{N}$ & 15 & 17 \\
\hline Mealid & 2 & 0 \\
\hline Missing & 62,6667 & 78,6471 \\
\hline Std. Error of Mean & 2,83963 & 2,31514 \\
\hline Median & 65,0000 & 75,0000 \\
\hline Mode & 70,00 & 75,00 \\
\hline Std. Deviation & 10,99784 & 9,54556 \\
\hline Variance & 120,952 & 91,118 \\
\hline Skewness &,- 284 &, 682 \\
\hline Std. Error of Skewness &, 580 &, 550 \\
\hline Kurtosis & $-1,303$ &,- 610 \\
\hline Std. Error of Kurtosis & 1,121 & 1,063 \\
\hline Range & 35,00 & 32,00 \\
\hline Minimum & 45,00 & 65,00 \\
\hline Maximum & 80,00 & 97,00 \\
\hline Sum & 940,00 & 1337,00 \\
\hline
\end{tabular}

Dari tabel 3.4 dapat diperoleh informasi secara deskripsi bahwa data yang diambil sebagai post-test memiliki rata-rata yang selisihnya cukup jauh dimana rata-rata nilai post-test untuk kelas kontrol sebesar 62,6667 sedangkan rata-rata nilai post-test untuk kelas eksperimen sebesar 78,6471. Meskipun demikian pembuktian hipotesis bahwa kedua kelas memiliki perbedaan yang signifikan akan dibahas pada sub bab berikutnya. Standar deviasi untuk kelas kontrol sebesar 10,99784 atau $17,55 \%$ dari rata-rata sedangkan untuk kelas ekperimen sebesar 9,54556 atau 12,14\% dari nilai rata-ratanya. Nilai tersebut tidak cukup besar (dibawah $20 \%$ dari nilai mean) menunjukan variasi yang relatif kecil.

\subsection{Analisis Data}

Dalam teknik pengujian hipotesis khususnya pada penelitian eksperimen, maka pengujian yang dilakukan harus memenuhi beberapa prosedur pengujian diantaranya uji prasyarat yang meliputi uji normalitas data dan uji homogenitas (kesamaan varian). Uji homogenitas mulak diperlukan pada penelitian dengan teknik Nonequivalent Control Group Design khusus untuk data sebelum (treatment) untuk meyakinkan bahwa data yang akan dibandingkan memiliki variasi yang sama antar kelompok sebelum diberikan perlakuan, sedangkan normalitas data menentukan jenis pengujian yang digunakan apakah menggunakan statistik parametrik maupun non-parametrik. Statistik parametrik digunakan untuk data yang berdistribusi normal sedangkan non-parametrik sebaliknya.

Pengujian dilakukan untuk kedua kelompok data baik data pada skor pre-test maupun pada skor post-test. 


\subsubsection{Analisis Data Pre-Test}

\section{a. Uji Prasyarat}

1. Uji Normalitas Data Pre-Test

Dengan menggunakan bantuan software IBM SPSS 25 diperoleh output sebagai berikut:

Tabel 3.5 Normalitas Data Pre-Test

\section{Tests of Normality}

\begin{tabular}{ll|r|r|r|r|r|r} 
& & & \multicolumn{3}{c|}{ Kolmogorov-Smirnova } & \multicolumn{3}{c}{ Shapiro-Wilk } \\
& Kelompok Kelas & Statistic & df & \multicolumn{1}{c}{ Sig. } & Statistic & \multicolumn{1}{c}{ df } & \multicolumn{1}{c}{ Sig. } \\
\hline $\begin{array}{l}\text { Nilai pre- } \\
\text { test }\end{array}$ & Kelas Kontrol &, 162 & 15 &, $200^{*}$ &, 963 & 15 &, 741 \\
\cline { 2 - 9 } & Kelas &, 189 & 17 &, 107 &, 939 & 17 &, 312 \\
\hline
\end{tabular}

${ }^{\star}$. This is a lower bound of the true significance.

a. Lilliefors Significance Correction

Hipotesis

$\mathrm{H}_{0} \quad$ : Data berdistribusi normal

$\mathrm{H}_{\mathrm{a}} \quad$ : Data tidak berdistribusi normal

Dari tabel 3.5 diketahui bahwa nilai sig. pada kolom Shapiro-Wilk untuk kelas kontrol sebesar 0,741 dan kelas eksperimen sebesar 0,312 dimana nilai sig. kedua kelas tersebut lebih besar dari 0,05 (sig. >0,05), maka $\mathrm{H}_{0}$ diterima. Dengan demikian data untuk skor pre-test baik kelas kontrol maupun kelas eksperimen berdistribusi normal.

\section{Uji Homogenitas Data}

Dengan menggunakan bantuan software IBM SPSS 25 diperoleh output uji homogenitas data sebagai berikut:

Tabel 3.6 Homogenitas Data Pre-Test

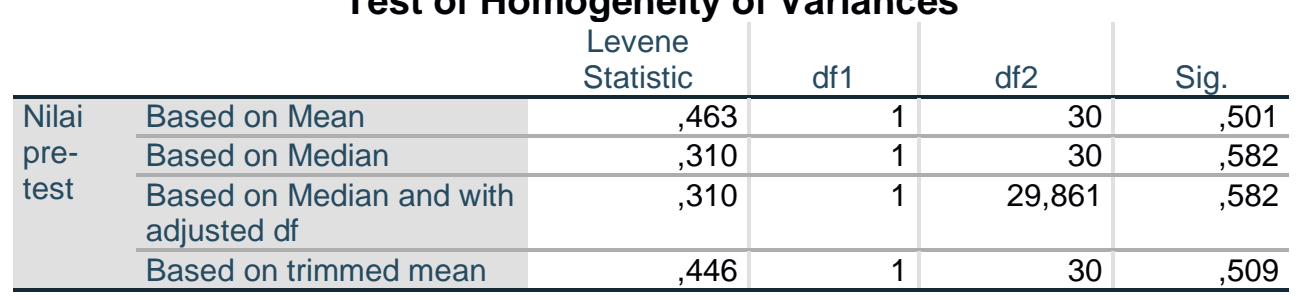

$\mathrm{H}_{0} \quad$ : Varians antara kelas kontrol dengan kelas eksperimen sama (homogen)

$\mathrm{H}_{\mathrm{a}} \quad$ : Varians antara kelas kontrol dengan kelas eksperimen tidak sama (tidak homogen) 
Dari tabel 3.6 diketahui bahwa nilai sig. pada tabel Test of Homogeneity of Variances pada baris Based on Mean sebesar 0,501 dimana nilai sig. tersebut lebih besar dari 0,05 (sig. >0,05), maka $\mathrm{H}_{0}$ diterima. Dengan demikian data untuk skor pre-test baik kelas kontrol maupun kelas eksperimen datanya homogen (varians sama).

\section{b. Uji Selisih Rata-Rata}

Dari hasil perhitungan uji prasayarat baik uji normalitas data maupun homogenitas data, dimana data berdistribusi normal dan memiliki variasi yang sama (homogen) maka pengujian selisih rata-rata dapat menggunakan uji-T untuk sampel bebas atau tidak berpasangan dan menggunakan baris Equal Variance Assumed pada pemilihan nilai signifikansinya.

Untuk output uji-t bantuan software IBM SPSS 25 sebagai berikut:

Tabel 3.7 Uji-T Untuk Pre-test

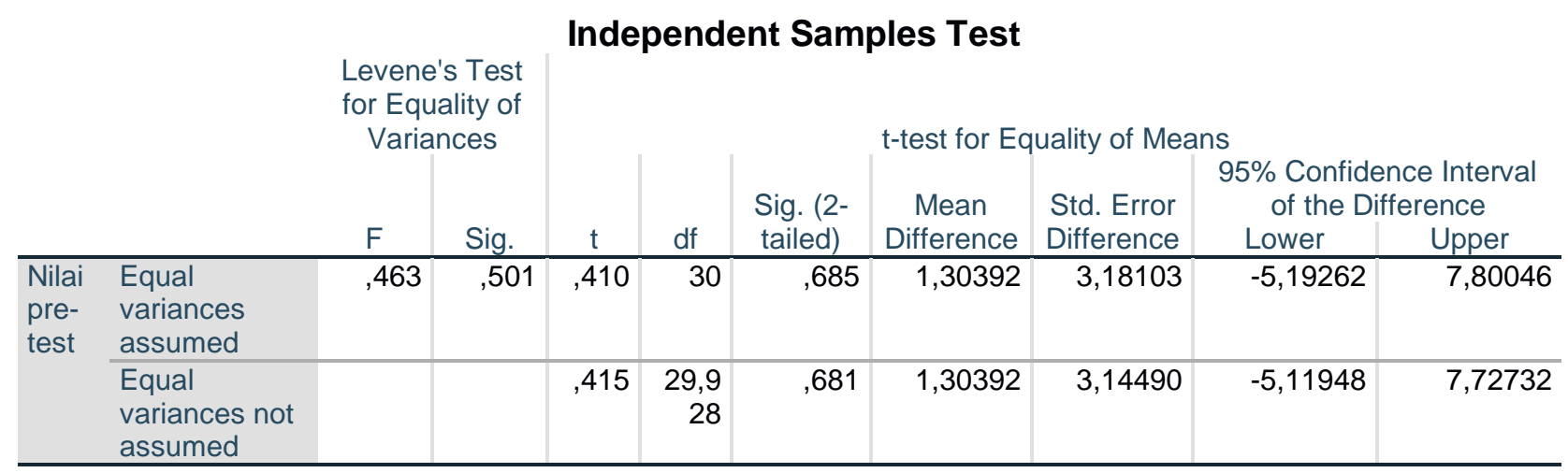

$\mathrm{H}_{0} \quad$ : Tidak terdapat perbedaan yang signifikan hasil belajar geometri analitik antara kelas kontrol dengan kelas eksperimen sebelum diberikan treatment.

$\mathrm{H}_{\mathrm{a}}$ : Terdapat perbedaan yang signifikan hasil belajar geometri analitik antara kelas kontrol dengan kelas eksperimen sebelum diberikan treatment.

Dari tabel 3.7 diketahui bahwa nilai sig. pada baris Equal variances assumed sebesar 0,685 dimana nilai sig. tersebut lebih besar dari 0,05 (sig. >0,05), maka $\mathrm{H}_{0}$ diterima. Dengan demikian tidak terdapat perbedaan yang signifikan hasil belajar geometri analitik antara kelas kontrol dengan kelas eksperimen sebelum diberikan treatment.

Dapat disimpulkan dari output di atas bahwa sebelum diberikan perlakuan atau treatment berupa pembelajaran dengan menggunakan media/ perangkat lunak atau software Graph 4.4.2 kedua kelas memiliki nilai rata-rata kelas yang sama atau tidak jauh berbeda. Sehingga ekperimen pembelajaran dengan menggunakan software 
Graph 4.4.2 dapat dilakukan untuk kelas ekperimen untuk membuktikan hipotesis bahwa pemanfaatan software Graph 4.4.2 dapat meningkan hasil belajar mahasiswa matematika khususnya terkait mata kuliah Geometri Analitik.

\subsubsection{Analisis Data Post-Test}

\section{a. Uji Prasyarat}

\section{Uji Normalitas Data Post-Test}

Dengan menggunakan bantuan software IBM SPSS 25 diperoleh output Normalitas data sebagai berikut:

Tabel 3.8 Normalitas Data Post-Test

\begin{tabular}{|c|c|c|c|c|c|c|c|}
\hline & \multicolumn{7}{|c|}{ Tests of Normality } \\
\hline & & \multicolumn{3}{|c|}{ Kolmogorov-Smirnova } & \multicolumn{3}{|c|}{ Shapiro-Wilk } \\
\hline & Kelompok Kelas & Statistic & df & Sig. & Statistic & df & Sig. \\
\hline Nilai & Kelas Kontrol & ,214 & 15 &, 062 & ,891 & 15 & ,069 \\
\hline $\begin{array}{l}\text { post- } \\
\text { test }\end{array}$ & $\begin{array}{l}\text { Kelas } \\
\text { Eksperimen }\end{array}$ & ,237 & 17 & ,012 & ,906 & 17 & ,084 \\
\hline
\end{tabular}

Hipotesis

$\mathrm{H}_{0} \quad$ : Data berdistribusi normal

$\mathrm{H}_{\mathrm{a}}$ : Data tidak berdistribusi normal

Dari tabel 3.8 diketahui bahwa nilai sig. pada kolom Shapiro-Wilk untuk kelas kontrol sebesar 0,069 dan kelas eksperimen sebesar 0,084 dimana nilai sig. kedua kelas tersebut lebih besar dari 0,05 (sig. >0,05), maka $\mathrm{H}_{0}$ diterima. Dengan demikian data untuk skor post-test baik kelas kontrol maupun kelas eksperimen berdistribusi normal. Bila diperhatikan lebih seksama, nilai signifikansinya mendekati 0,05 yang berarti distribusi data tidak menyebar terlalu jauh dari ratarata, dan itu terjadi baik di kelas kontrol maupun di kelas eksperimen.

2. Uji Homogenitas Data

Dengan menggunakan bantuan software IBM SPSS 25 diperoleh output uji homogenitas data sebagai berikut:

Tabel 3.9 Homogenitas Data Post-Test

\begin{tabular}{|c|c|c|c|c|c|}
\hline \multicolumn{6}{|c|}{ Test of Homogeneity of Variances } \\
\hline & & $\begin{array}{l}\text { Levene } \\
\text { Statistic }\end{array}$ & $\mathrm{df1}$ & $\mathrm{df} 2$ & Sig. \\
\hline \multirow{4}{*}{$\begin{array}{l}\text { Nilai post- } \\
\text { test }\end{array}$} & Based on Mean & ,845 & 1 & 30 & ,365 \\
\hline & Based on Median &, 581 & 1 & 30 & ,452 \\
\hline & $\begin{array}{l}\text { Based on Median and with } \\
\text { adjusted df }\end{array}$ &, 581 & 1 & 29,607 & ,452 \\
\hline & Based on trimmed mean & ,872 & 1 & 30 & ,358 \\
\hline
\end{tabular}


$\mathrm{H}_{0} \quad$ : Varians antara kelas kontrol dengan kelas eksperimen sama (homogen)

$\mathrm{H}_{\mathrm{a}}$ : Varians antara kelas kontrol dengan kelas eksperimen tidak sama (tidak homogen)

Dari tabel 3.9 diketahui bahwa nilai sig. pada tabel Test of Homogeneity of Variances pada baris Based on Mean sebesar 0,365 dimana nilai sig. tersebut lebih besar dari 0,05 (sig. >0,05), maka $\mathrm{H}_{0}$ diterima. Dengan demikian data untuk skor pre-test baik kelas kontrol maupun kelas eksperimen datanya homogen (varians sama).

\section{b. Uji Selisih Rata-Rata}

Dari hasil perhitungan uji prasayarat baik uji normalitas data maupun homogenitas data, dimana data berdistribusi normal dan memiliki variasi yang sama (homogen) maka pengujian selisih rata-rata dapat menggunakan uji-t untuk sampel bebas atau tidak berpasangan dan menggunakan baris Equal Variance Assumed pada pemilihan nilai signifikansinya.

Dengan menggunakan bantuan software IBM SPSS 25 diperoleh output uji-T sebagai berikut:

Tabel 3.10 Uji T Untuk Post-test

\begin{tabular}{|c|c|c|c|c|c|c|c|c|c|c|}
\hline & & \multicolumn{2}{|c|}{$\begin{array}{l}\text { Levene's } \\
\text { Test for } \\
\text { Equality of } \\
\text { Variances }\end{array}$} & \multicolumn{7}{|c|}{ t-test for Equality of Means } \\
\hline & & & & & & $\begin{array}{l}\text { Sig. } \\
(2-\end{array}$ & Mean & Std. Error & $\begin{array}{r}95 \% \text { Cor } \\
\text { Interva } \\
\text { Differ }\end{array}$ & $\begin{array}{l}\text { fidence } \\
\text { of the } \\
\text { nce }\end{array}$ \\
\hline & & $\mathrm{F}$ & Sig. & $\mathrm{t}$ & $\mathrm{df}$ & tailed) & Difference & Difference & Lower & Upper \\
\hline \multirow[t]{2}{*}{$\begin{array}{l}\text { Nilai } \\
\text { post- } \\
\text { test }\end{array}$} & $\begin{array}{l}\text { Equal } \\
\text { variances } \\
\text { assumed }\end{array}$ & ,845 & ,365 & $-4,402$ & 30 &, 000 & $-15,98039$ & 3,63064 & $-23,39515$ & $-8,56563$ \\
\hline & $\begin{array}{l}\text { Equal } \\
\text { variances } \\
\text { not } \\
\text { assumed }\end{array}$ & & & $-4,362$ & $\begin{array}{r}27,9 \\
80\end{array}$ & ,000 & $-15,98039$ & 3,66379 & $-23,48556$ & $-8,47522$ \\
\hline
\end{tabular}

$\mathrm{H}_{0} \quad$ : Rata-rata hasil belajar geometri analitik kelas eksperimen tidak lebih baik dibandingkan kelas kontrol..

$\mathrm{H}_{\mathrm{a}}$ : Rata-rata hasil belajar geometri analitik kelas eksperimen lebih baik dibandingkan kelas kontrol.

Dari tabel 3.10 diketahui bahwa nilai sig. pada baris Equal variances assumed sebesar 0,000 dimana nilai sig. tersebut lebih kecil dari 0,05 (sig. <0,05), maka $\mathrm{H}_{0}$ 
ditolak. Dengan demikian rata-rata hasil belajar geometri analitik kelas eksperimen lebih baik dibandingkan kelas kontrol.

Dapat disimpulkan dari output di atas bahwa setelah diberikan perlakuan atau treatment berupa pembelajaran dengan menggunakan media/perangkat lunak atau software Graph 4.4.2 kelas eksperimen memperoleh nilai rata-rata yang lebih baik dibandingkan dengan kelas kontrol. Sehingga ekperimen pembelajaran dengan menggunakan software Graph 4.4.2 membenarkan asumsi bahwa dengan pemanfaatan media yang baik akam mampu meningkatkan hasil belajar mahasiswa khususnya dalam bidang geometri terutama geometri analitik.

\subsubsection{Uji Normalitas Gain}

Untuk mengetahui seberapa efektif penggunaan software graph 4.4 .2 dalam meningkatkan pemahaman materi geometri analitik melalui ujian tertulis menggunakan Uji Normalitas Gain. Tabel berikut hasil perhitungan Normalitas Gain dengan menggunakan Microsoft Excel.

Tabel 3.11 Uji Normalitas Gain

\begin{tabular}{|c|c|c|c|c|c|c|}
\hline \multirow{2}{*}{ No } & \multicolumn{2}{|c|}{ Pre-Test } & \multicolumn{2}{c|}{ Post-Test } & \multicolumn{2}{c|}{ Gain Score } \\
\cline { 2 - 7 } & $\mathbf{O}_{1}$ & $\mathbf{O}_{\mathbf{2}}$ & $\mathbf{O}_{3}$ & $\mathbf{O}_{4}$ & $\begin{array}{c}\text { Kelas } \\
\text { Kontrol }\end{array}$ & $\begin{array}{c}\text { Kelas } \\
\text { Eksperimen }\end{array}$ \\
\hline 1 & 27,5 & 25 & 50 & 70 & 0,43 & 0,63 \\
\hline 2 & 35 & 45 & 70 & 90 & 0,78 & 0,87 \\
\hline 3 & 15 & 30 & 45 & 75 & 0,46 & 0,67 \\
\hline 4 & 35 & 25 & 75 & 75 & 0,89 & 0,69 \\
\hline 5 & 25 & 25 & 50 & 65 & 0,45 & 0,56 \\
\hline 6 & 32,5 & 30 & 65 & 75 & 0,68 & 0,67 \\
\hline 7 & 42,5 & 17,5 & 80 & 70 & 1,00 & 0,66 \\
\hline 8 & 40 & 15 & 70 & 70 & 0,75 & 0,67 \\
\hline 9 & 20 & 30 & 50 & 80 & 0,50 & 0,75 \\
\hline 10 & 35 & 25 & 70 & 70 & 0,78 & 0,63 \\
\hline 11 & 30 & 40 & 70 & 97 & 0,80 & 1,00 \\
\hline 12 & 45 & 25 & 65 & 75 & 0,57 & 0,69 \\
\hline 13 & 37,5 & 32,5 & 70 & 85 & 0,76 & 0,81 \\
\hline 14 & 30 & 30 & 60 & 75 & 0,60 & 0,67 \\
\hline 15 & 35 & 45 & 50 & 90 & 0,33 & 0,87 \\
\hline 16 & & 37,5 & & 80 & & 0,71 \\
\hline 17 & & 50 & & 95 & & 0,96 \\
\hline Rerata & 32,33 & 31,03 & 62,67 & 78,65 & 0,65 & 0,74 \\
\hline Min & 15 & 15 & 45 & 65 & & \\
\hline Max & 45 & 50 & 80 & 97 & & \\
\hline
\end{tabular}


Dari tabel 4.11 dapat diketahui nilai Gain rata-rata kelas eksperimen sebesar 0,74 dan nilai ini lebih besar dari 0,7 maka gain-nya dapat dikategorikan tinggi.

Hasil ini memperkuat hasil uji selisih rata-rata (uji-T) post-test dimana dengan adanya pembelajaran berbantu perangkat lunak Graph 4.4.2 pembelajaran menjadi lebih hidup, lebih interaktif dan mahasiswa akan memiliki pengalaman belajar yang lebih baik khususnya bagi mereka yang kesulitan dalam menggambarkan maupun memvisualisaikan persamaan dalam geometri. Selain itu waktu yang diperlukan dalam membahas perkasus menjadi lebih lama dikarenakan dosen maupun mahasiswa tidak membutuhkan waktu yang lama untuk menggambar, karena ketersediaan perangkat lunak ini.

\section{SIMPULAN DAN SARAN}

Simpulan penelitian ini yaitu:

1) Terdapat perbedaan yang signifikan antara hasil belajar sebelum menggunakan software graph 4.4.2 dengan hasil belajar setelah menggunakan software graph 4.4.2 dalam perkuliahan geometri analitik, dimana rata-rata nilai kelas eksperimen yang menggunakan software graph 4.4.2 dalam proses pembelajaran jauh lebih baik dibandingan dengan kelas kontrol yang dalam proses belajar tanpa menggunakan software graph 4.4.2. Hal ini dibuktikan dari nilai sig. pada uji-t sebesar 0,000 dan nilai thitung sebesar 4,402 .

2) Pemanfaatan software graph 4.4.2 sangat efektif dalam menunjang perkuliahan geometri analitik, hal ini dibuktikan dari skor gain rata-rata sebesar 0,74. Skor gain rata-rata $>0,7$ merupakan kategori tinggi dalam menentukan perbedaan sebelum dan sesudah treatment.

\section{DAFTAR PUSTAKA}

Bix , R. A., \& D'Souza, H. J. (n.d.). Algebraic Geometry. Retrieved from Encyclopædia Britannica: https://www.britannica.com/science/algebraic-geometry

Farihah, U. (2015, September). Pengaruh Program Interaktif Geogebra Terhadap Motivasi Dan Hasil Belajar Siswa Pada Materi Grafik Persamaan Garis Lurus. Jurnal Pendidikan dan Pembelajaran Matematika (JP2M), 1(1), 11-23. doi:10.29100/jp2m.v1i2.190

Geometri Analitik. (n.d.). Retrieved from https://id.wikipedia.org/wiki/Geometri_analitis Geometry. (n.d.). Retrieved from Wikipedia: https://en.wikipedia.org/wiki/Geometry

Geometry Definition. (n.d.). Retrieved from Oxford Dictionaries: https://en.oxforddictionaries.com/definition/geometry 
Heilbron, J. L. (n.d.). Geometry. Retrieved from Encyclopædia Britannica: https://www.britannica.com/science/geometry

Hidayat, A. (2014, August 6). Pilihan Uji Normalitas Univariate. Retrieved from Statistikian: $\quad$ https://www.statistikian.com/2014/08/pilihan-uji-normalitasunivariate.html

Iswanto, D. (2012, August 7). Definisi Geometri. Retrieved from Matematika Dedi: https://matematikadedi.wordpress.com/2012/08/07/definisi-geometri/

KBBI. (2008). Jakarta: Pusat Bahasa Departemen Pendidikan Nasional.

Kurniawan, A. (2011). SPSS Serba-Serbi Analisis Statistika Dengan Cepat dan Mudah. Jakarta: Jasakom.

Muhassanah, N., Sujadi, I., \& Riyadi. (2014, March). Analisis Keterampilan Geometri Siswa Dalam Memecahkan Masalah Geometri Berdasarkan Tingkat Berpikir Van Hiele. Jurnal Elektronik Pembelajaran Matematika, 2(1), 54-66. Retrieved from http://jurnal.fkip.uns.ac.id/index.php/s2math/article/view/3639

Nur, I. M. (2016, April). Pemanfaatan Program Geogebra Dalam Pembelajaran Matematika. Delta-Pi: Jurnal Matematika dan Pendidikan Matematika, 10-19. Retrieved from http://ejournal.unkhair.ac.id/index.php/deltapi/article/view/236/0

Nur'aini, I. L., Harahap, E., Badruzzaman, F. H., \& Darmawan, D. (2017, December). Pembelajaran Matematika Geometri Secara Realistis Dengan GeoGebra. Jurnal Matematika, 16(2), 1-6. Retrieved from https://ejournal.unisba.ac.id/index.php/matematika/article/view/3900

Sadiman, A. S., Rahardjo, R., Haryono, A., \& Rahardjito. (2012). Media Pendidikan. Depok: RajaGrafindo Persada.

Setiawan, N. (2005). Statistika Nonparametrik Untuk Penelitian Sosial Ekonomi Peternakan. Bandung: Fakultas Peternakan Universitas Padjadjaran.

Suarsana, I. M. (2014). Geometri Analitik. Yogyakarta: Graha Ilmu.

Sugiyono. (2010). Metode Penelitian Kuantitatif Kualitatif dan R\&D. Bandung: Alfabeta.

Sugiyono. (2017). Statistika Untuk Penelitian. Bandung: Alfabeta.

Sundayana, R. (2014). Statitika Penelitian Pendidikan. Bandung: Alfabeta.

Supardi. (2012). Aplikasi Statistika dalam Penelitian (Buku Statistika Yang Paling Komprehensif). Jakarta: Ufuk Press.

Yulianto, M. A. (2012, August 31). Uji Levene. Retrieved from Digensia: https://digensia.wordpress.com/2012/08/31/uji-levene/ 
Zarkasih, R. R. (2017, April 10). Geometri Analitik. Retrieved from https://rahmarozazarkasih17.blogspot.com/2017/04/11-sejarah-geometrianalitik.html 